\title{
A study of knowledge, attitude and practice of mothers on immunization of children in urban slums
}

\author{
Tiwari A. ${ }^{1}$, Vishwakarma K. ${ }^{2}$ \\ ${ }^{1}$ Dr Astha Tiwari, Associate Professor, ${ }^{2}$ Dr Kirti Vishwakarma, Assistant Professor, both authors are affiliated with \\ Department of Pediatrics R.K.D.F Medical College, Bhopal, MP, India
}

Correspondence Author: Dr Kirti Vishwakarma, Assistant Professor, Department of Pediatrics, R.K.D.F Medical College, Bhopal, India. E-mail: kirtivishvakarma6@gmail.com

\begin{abstract}
Background and Objective: Vaccination is a cost-effective intervention to prevent major illness that contribute to child mortality in the country. Increase in parental knowledge about vaccination will lead to increase in vaccination rates of children. Urban slums constitute one of the high-risk areas of vaccine preventable diseases. The main objective of the study was to determine the mother's knowledge towards childhood immunization and to assess the reasons for incomplete immunization. Material and Methods: A community based, cross-sectional study was conducted in the urban slums of Bhopal city, India. Out of the enlisted slums, 5 slums were chosen. House to house survey was done. After obtaining oral consent, information regarding knowledge, attitude and practices was collected by using a proforma. Results: A total of 300 children in the age group of 0 to 24 months were included in the study. 154 Children out of 300 $(51.33 \%)$ were fully immunized, $67(22.33 \%)$ were partially immunized and $79(26.33 \%)$ were unimmunized. Majority of the mothers $(83.6 \%)$ showed positive attitude towards getting their child. About $15.6 \%$ participants had the misconception of stopping the immunization if it caused side effects Majority $60 \%$ of mothers were unaware about the age-related vaccination. The main reason for partial and non-immunization was found to be lack of information poor infrastructure. Conclusion: Immunization coverage in the urban slums of Bhopal is still short compared to national standards. A lack of information and motivation among the parents is the main reason for this dismal scenario, that needs to be rectified at the earliest
\end{abstract}

Keywords: Immunization, Anganwadi workers, Attitude, Urban slum

\section{Introduction}

Immunization is one of the most cost-effective public health interventions since it provides direct and effective protection against preventable morbidity and mortality. It has been a major contributor in the decline of under-5 mortality rate from 233 to 63 (per 1000) in the last five decades in India [1,2]. However, vaccine preventable diseases (VPDs) are still responsible for over 5 lakh deaths annually in India [3,4]. In May 1974, the WHO launched the Expanded Immunization Program (EPI) globally, with a focus on prevention of 6 vaccine-preventable diseases by the year 2000. In India, EPI was launched in 1978 and it was re-designated as the Universal Immunization Program (UIP) in 1985, with a goal to cover at least $85 \%$ of infants [5]. Infant mortality rate (IMR) is considered as one of the most

Manuscript received: $11^{\text {th }}$ October 2019

Reviewed: $21^{\text {st }}$ October 2019

Author Corrected: $26^{\text {th }}$ October 2019

Accepted for Publication: $31^{\text {st }}$ October 2019 sensitive indicators of health status of a community. Infant mortality figures in India are very high. According to NFHS 4 [6] survey the IMR in India is 41 per 1000 live births and under five mortality rates is 50 .

The data from Madhya Pradesh indicates a high IMR 51 per 1000 live births and under five mortality rate 65 which is much higher as compared to national statistics Despite India being a leading producer of vaccines, it harbors one-third of the world's unimmunized children [2]. Despite the fact that the scheduled immunization vaccines are provided free of cost at a majority of government run health facilities. Lack of information and knowledge, and fear of vaccine adverse effects among the mothers and communities at large is a major barrier to vaccination coverage $[4,5]$. Negative parental perceptions of vaccination are also an important barrier to childhood vaccination. 


\section{Original Research Article}

Since mothers are the primary caregivers to the child, interventions targeted towards them can prove more effective [6].

The situation of under immunization is not only in the rural areas of the country, but also in urban areas as the migration of workers and the mushrooming of slums in urban areas are occurring at a rapid rate, and these are areas with unprecedented poverty, illiteracy, overcrowding and disease [7].

The main objective of the present study was to assess the mothers' knowledge, attitude and practices regarding immunization and to determine factors associated with a child's immunization status.

\section{Objectives}

1.To determine the knowledge, attitude and practices of mothers on immunization of children in urban slums.

2 . To assess the reasons for incomplete immunization

\section{Materials and Methods}

Study design/type of study - A community based, cross-sectional study was conducted in the urban slums of Bhopal city, India
Sample size \& duration of study- A total of 300 children in the age group of 0 to 24 months were included in the study. Study conducted by the Department of Pediatrics, RKDF Medical College, Bhopal in urban slums around the college. The study was conducted during a period of 3 months.

Inclusion criteria: Mothers of total 300 children in the age group of 0 to 24 months were included in the study

Data collection procedure: Out of the enlisted slums, 5 slums were chosen. House to house survey was done. After obtaining oral consents, A pretested structured questionnaire including socio demographic profile of mother was used to elicit Information about child's Immunization status, the mothers' knowledge of vaccine preventable diseases and any perceived barriers to vaccinate the child was noted. information regarding knowledge, attitude and practices was collected by using a proforma.

Statistical data analysis: The necessary tables and graphs were prepared, the data was analyzed manually in the initial stages, and later computerized analysis was done using Percentage and chi square. $\mathrm{p}$ value.P $<0.05$ was taken as statistically significant.

\section{Results}

Total of 300 mothers of children in the age group of 0 to 24 months were included in the study. Male children were 115 $(50.32 \%)$ and female $106(49.68 \%)$. Majority of mothers (55.48\%) were in a group 21-25 years. $146(48.66 \%)$ mothers were illiterate, $42 \%$ educated till secondary school. Pre-college and graduate were $1.33 \%$ and $0.65 \%$ respectively (Table 1).

Majority 55.48\% belong to grade four socioeconomic status (Table-2). 232 (77.33\%) of mothers were housewives, and $14.66 \%$ worked on daily wages, $8 \%$ were employed.

154 Children out of $300(51.33 \%)$ were fully immunized, 67 (22.33\%) were partially immunized and $79(26.33 \%)$ were unimmunized. $161(72.85 \%)$ mothers had immunization card. while $60(27.15 \%)$ do not had immunization card at the time of survey.

A large proportion of the children $182(82.35 \%)$ had received their immunization from government establishment and $39(17.64 \%)$ from private hospital or clinic (Table-3).

None of the mothers could name all the EPI disease. The highest number (82\%) named Polio and nearly $75 \%$ knew about the measles vaccine (Table-4).

Majority of the mothers (83.6\%) showed positive attitude towards getting their child immunized and almost $(87.8 \%)$ believed that immunization is important for their children and it prevents disease in children and. About $15.6 \%$ of participants had the misconception of stopping the immunization if it caused side effects.

Nearly Fifty one percent of the respondents knew that the child should be vaccinated even if it had minor illness during the time of immunization. $88.6 \%$ mothers were aware of the fact that vaccination should be given at birth (Table-5).

Pediatric Review: International Journal of Pediatric Research Available online at: www.medresearch.in 548|P a g e 
Table-1: Distribution of socio-demographic indicators of the respondents

\begin{tabular}{|l|c|c|}
\hline Socio-demographic indicators & Mother $(\mathbf{n}=\mathbf{3 0 0})$ & Percentage \\
\hline Age & & $(20.65)$ \\
\hline$<20$ Years & 62 & $(55.48)$ \\
\hline $21-25$ Years & 124 & $(6.45)$ \\
\hline $26-30$ Years & 80 & 1.33 \\
\hline $31-35$ Years & 29 & $(48.66)$ \\
\hline $36-40$ years & 4 & $(7.33)$ \\
\hline$>40$ years & 1 & $(42)$ \\
\hline Education & & $(1.33)$ \\
\hline Illiterate & 146 & $(0.65)$ \\
\hline Primary School & 22 & $(126$ \\
\hline Secondary School & 4 & $(14.33)$ \\
\hline Pre-college & 2 & $(8)$ \\
\hline Graduate & & $(14.66)$ \\
\hline Occupation & 232 & 19 \\
\hline Unemployed/housewife & 44 & \\
\hline Daily wage & 24 & \\
\hline Employed & 243 & \\
\hline Place of delivery & 57 & \\
\hline Healthcare facility & & \\
\hline Home & & \\
\hline
\end{tabular}

Table-2: Socio-economic status B.G. prasad classification.

\begin{tabular}{|c|c|}
\hline Socio-economic Status B.G. Prasad classification & $(\mathbf{n}=\mathbf{3 0 0})$ \\
\hline 1 & 0 \\
\hline 2 & $37(10.97 \%)$ \\
\hline 3 & $113(18.06 \%)$ \\
\hline 4 & $126(55.48 \%)$ \\
\hline 5 & $24(15.48 \%)$ \\
\hline
\end{tabular}

Table-3: Immunization details of children aged 0-24 months.

\begin{tabular}{|c|c|}
\hline Immunization details & No. of children (n=300) \\
\hline Immunization Status & $154(51.33 \%)$ \\
\hline Fully immunized & $67(22.33 \%)$ \\
\hline Partially immunized & $79(26.33 \%)$ \\
\hline Unimmunized & $42(13.75 \%)$ \\
\hline T.V. and media & $137(45.65 \%)$ \\
\hline Health Worker (ANM/AWW) & $52(17.42 \%)$ \\
\hline Doctor & $69(23.18 \%)$ \\
\hline Family/Relatives & $115(50.32 \%)$ \\
\hline Male conild & $106(49.68 \%)$ \\
\hline Female & $\mathrm{N}=221$ \\
\hline Immunization card & $161(72.85 \%)$ \\
\hline Has card & $60(27.15 \%)$ \\
\hline Does not have card & $\mathrm{N}=221$ \\
\hline Place of receiving immunization & $182(82.35 \%)$ \\
\hline Government organization & $39(17.64 \%)$ \\
\hline Private hospital/Clinic & \\
\hline
\end{tabular}


Table-4: EPI diseases named by participants.

\begin{tabular}{|c|c|c|}
\hline Vaccine preventable diseases & Number $\mathbf{n}=\mathbf{3 0 0}$ & Percentage \\
\hline Polio & 246 & 82 \\
\hline Tuberculosis & 90 & 30 \\
\hline Diphtheria & 45 & 15 \\
\hline Tetanus & 84 & 28 \\
\hline Pertussis & 45 & 15 \\
\hline Measles & 225 & 75 \\
\hline Hepatitis & 105 & 35 \\
\hline
\end{tabular}

Table-5: Knowledge, attitude $\&$ awareness about immunization among mothers $(n=300)$.

\begin{tabular}{|c|c|c|c|}
\hline Knowledge assessment questions & Yes $(\%)$ & No $(\%)$ & Don't know (\%) \\
\hline Knowledge regarding vaccination & 83.3 & 11.9 & 4.8 \\
\hline Vaccine should be given at birth & 88.6 & 2.4 & 9 \\
\hline Vaccine prevents disease & 87.8 & 2.2 & 10 \\
\hline Vaccine are harmful and cause side effects & 15.6 & 75.3 & 9.1 \\
\hline Vaccine can be given in cough and cold & 52 & 35 & 13 \\
\hline Vaccine can be given if child has fever & 56.7 & 40 & 3.3 \\
\hline Child with diarrhea can be vaccinated & 48.4 & 38 & 13.6 \\
\hline \multicolumn{4}{|c|}{ Attitude towards immunization among primigravida } \\
\hline Will get my child completely immunized & $80.3 \%$ & & \\
\hline Will follow vaccination schedule & $70.5 \%$ & & \\
\hline
\end{tabular}

221 mothers of partially immunized and unimmunized children reported various reasons for incomplete immunization. Majority $60 \%$ of mothers were unaware about the age-related vaccination whereas $28 \%$ mothers quoted domestic work as a reason for not getting time to vaccinate (Table-6).

Table-6: Reasons reported for incomplete immunization.

\begin{tabular}{|l|c|}
\hline Reasons for incomplete immunization & Percentage \\
\hline Mother was busy/Domestic work & 28 \\
\hline Child as unwell at the time of vaccination & 15.5 \\
\hline Long waiting time for immunization & 26.8 \\
\hline Mother was afraid of side effects & 10.1 \\
\hline Unaware of optional vaccine & 60 \\
\hline Mother was unaware of age-related vaccination & 12 \\
\hline Health staff absent & 24 \\
\hline Vaccine was not available at the centre & 12 \\
\hline Child got fever from the previous vaccine & 15 \\
\hline Lack of escort & 4.5 \\
\hline Did not know the place and time for immunization & 24 \\
\hline
\end{tabular}




\section{Original Research Article}

When asked about the main source of information about immunization $45.65 \%$ quoted healthcare workers as the primary source of information. The association between immunization status and other demographic variables like mother's education, socioeconomic status and gender of the child was calculated. The association between mother's education and immunization was statistically significant while that of mother's socioeconomic status and gender of the child was found statistically not significant (Table-7).

Table-7: Comparison of immunization status with socio-demographic indicators.

\begin{tabular}{|c|c|c|c|}
\hline S No. & Socio-demographic indicator & $\begin{array}{l}\text { Fully immunized } \\
\qquad(\mathrm{N}=154)\end{array}$ & $\begin{array}{c}\text { Partially immunized and } \\
\text { unimmunized }(N=146)\end{array}$ \\
\hline \multirow[t]{4}{*}{1} & Mother Education & & \\
\hline & Uneducated & 26 & 40 \\
\hline & Primary School & 45 & 6 \\
\hline & Secondary school and above & 83 & 100 \\
\hline \multicolumn{4}{|c|}{ The chi-square statistic is 4.8282 . The $\mathrm{p}$-value is .027998 . This result is significant at $\mathrm{p}<.05$. (S) } \\
\hline \multirow[t]{5}{*}{2} & Socio-economic status & & \\
\hline & 2 & 25 & 12 \\
\hline & 3 & 42 & 36 \\
\hline & 4 & 80 & 79 \\
\hline & 5 & 7 & 17 \\
\hline \multicolumn{4}{|c|}{ Degree of freedom $=3$, Chi-Square $=1.354, p=0.7164(\mathrm{NS})$} \\
\hline \multirow[t]{3}{*}{3} & Sex of Child & & \\
\hline & Male & 86 & 78 \\
\hline & Female & 68 & 68 \\
\hline
\end{tabular}

\section{Discussion}

Despite all efforts put by the government as well as non-government institutes for $100 \%$ immunization coverage, there are still pockets of low coverage areas. Urban slums constitute one of the high-risk areas for vaccine preventable diseases [8-11].

Children of urban slum are highly exposed to outbreaks of vaccine preventable diseases due to high population density and continuous influx of infective agents in migratory population [12]. Maternal and child health indicators among slum-dwellers revealed that their health is 2-3 times worse than the people living in better urban areas [13-15].

The immunization coverage status in present study is $51.09 \%$ children are completely immunized , $22.33 \%$ are partially immunized and $26.33 \%$ were unimmunized According to NFHS-4 [6] data this figure is far less as compared to National statistics of immunization which is 62. But immunization it is more or less similar to statistics of fully immunized children in Madhya Pradesh which is $53.6 \%$. NFHS 4 [6]. In the study of Nath et al [7], $44.1 \%$ of children were fully immunized $32 \%$ and $23.9 \%$ were partially and unimmunized respectively.
Sharma et al reported fully immunized children were $25 \%$, partially and unimmunized children were $23.1 \%$ [16]. Thus, different studies conducted in urban slums showed a low vaccination coverage. which is an important area of concern.

In the present study assessment of knowledge of mothers about immunization showed wide gap in the knowledge and practice. About $83.3 \%$ participants knew about immunization and its benefits, of which the major source of information was health care workers $(45.65 \%)$. This was in concordance with the study by Nath et al [7]. This contradicts with the findings of study of Angadi et al [11], relatives and friends serve as major source of information (42.48\%) followed by healthcare workers such as auxiliary nurse midwives (34.19\%), and doctors.

This difference may be due to different biosocial demographics of the region. Various studies $[15,17]$ showed results similar to present study. The present study revealed that Anganwadi workers were the main source of information in the rural areas and it is this population that needs to be adequately trained so that they can spread the awareness up-to the doorstep of the

Pediatric Review: International Journal of Pediatric Research Available online at: www.medresearch.in 551|P a g e 


\section{Original Research Article}

population. These lacunae need to be filled in order to attain $100 \%$ vaccination coverage in the country especially in the urban slum areas rural areas.

In the present study maximum numbers of mothers (82\%) named Polio and $75 \%$ knew about measles but none could name all the VPD. Knowledge and awareness regarding complete immunization schedule at the primary healthcare level was emphasized in many studies [15,18]. Singh et al [19] reported in their study that mothers had fair knowledge regarding the need for immunization but had poor knowledge regarding vaccine preventable diseases. Mothers' inability to name or identify diseases other than poliomyelitis indicates that health education should be emphasized to enhance knowledge about the complete program. Further into the knowledge about vaccination most mothers believed vaccines were safe, however a large proportion of mother (35-40\%) delay vaccinating their child in the circumstances of simple childhood illnesses. These myths must be abolished.

In the present study it was also seen that immunization status of the children were significantly associated with educational status of mother and it is found to be statistically significant. but socioeconomic status of mother and the gender of the child had no statistically significant association with immunization status of the child.

This was similar to the findings of a study done by Bholanath et al [7], that found that maternal education and socioeconomic status were significant independent predictors of immunization status) .but in contrast to the findings of the study done by AM and Angadi et al [11], who found that though the coverage of all vaccines was slightly higher in males than in females, this association between education, socioeconomic status, gender was not statistically significant. This change has probably occurred due to the improved access to immunization and improved social mobilization of the health workers, that have helped us tackle previous barriers to immunization, such as illiteracy and low socio-economic status.

This study showed that most of the $82.35 \%$ mothers in urban slums preferred and trusted Government health facilities for vaccination of their child. while only $17.64 \%$ preferred nongovernment organizations. This is similar to results found $[11,17,20,21]$ studies. This was probably because of the expense that would be incurred in a private health facility which a mother with low socioeconomic status cannot afford.
The main reason for partial and non-immunization in the present study was found to be lack of information of mother regarding age related vaccination, lack of information, $60 \%$ mothers had lack of knowledge regarding immunization schedule, while $4.5 \%$ respondents said they did not know the place and /or time of immunization. $28 \%$ mothers delayed child's vaccination due to domestic work. A study by Kumar A [18] $99.5 \%$ felt that immunization is important for their child. Although the attitude was good among the participants, the levels can be further improved by providing awareness and health education.

An unfortunate fact was that though a vast majority of the population recognized the importance of immunization, a superficial knowledge of the schedule in the target population for completing the schedule, has led to a large proportion of the children being partially immunized.

Limitation of the present study- Children's immunization status was assessed by mother's recall so it may be subject to bias. Large sample size with better statistical analysis is needed.

\section{Conclusion}

The mothers' knowledge about vaccine preventable diseases and vaccination schedule was poor. Complete immunization rate among the children was low, It is evident from the present study that lack of appropriate knowledge and information is the main hurdle for the success of primary immunization and is the main reason for incomplete immunization.

Every immunization program should strive to provide quality services that are accessible, convenient, reliable, friendly, affordable and acceptable, and should solicit feedback from families and community leaders. Every program should monitor missed and under-vaccinated children and assess and address the causes. Every opportunity should be used to vaccinate children in these areas with the help of grass root level health workers to achieve the goal of $100 \%$ immunization coverage

\section{What this study adds to existing knowledge?}

This study goes out as a wakeup call for all policy makers and healthcare providers, in that, providing the resources for immunization alone is a job which is half done and that health education is also an essential 
component that can go a long way in improving the prevailing scenario of immunization in the country.

\section{Contribution by different authors}

Dr. Astha Tiwari: Concept and data collection

Dr. Kirti Vishwakarma: Data analysis and discussion

Funding: No funding required

Conflict of interest: No conflict of interest

Ethical approval: This study was approved by the Institutional Ethics Committee

\section{References}

1. World bank database Health Nutrition and Population Statistics. Available online at https://databank. worldbank. org/source/health-nutrition-and-populationstatistics.

2. Vashishtha VM, Kumar P. 50 years of immunization in India: progress and future. Indian Pediatr. 2013;50(1):111-118. doi: 10.1007/s13312-013-0025-0

3. WHO, 2015 Global Immunization Data. Available at https://www.who.int/immunization/monitoring_surveill ance/global_immunization_data.pdf

4. WHO, UNICEF, World Bank. State of the world's vaccines and immunization, 3rd ed. Geneva, World Health Organization, 2009. Available at http://www. unicef.org/ immunization/ files/SOWVI_full_report_

5. Ghei K, Agarwal S, Subramanyam MA, Subramanian SV. Association between child immunization and availability of health infrastructure in slums in India. Arch Pediatr Adole Med. 2010;164(3):243-249. doi: 10.1001/archpediatrics.2009.277.

6. National family health survey (NFHS4): Available at http://www.indiaenvironmentportal.org.in/content/4403 96/national-family-health-survey-2015-16-nfhs-4-indiafact-sheet.

7. Nath B, Singh JV, Awasthi S, Bhushan V, Kumar V, Singh SK. KAP study on immunization of children in a city of North India-a 30 cluster survey. Online J Health All Sci. 2008;7(1).

8. Kar M, Reddaiah VP, Kant S. Primary immunization status of children in slum areas of South Delhi-the Challenge of Reaching the urban poor. Indian J Comm Med. 2001;26(3):151-154.

\section{Original Research Article}

9. Lodha R, Dash NR, Kapil A, Kabra SK. Diphtheria in urban slums in north India. Lancet. 2000;355 (9199):204. doi: 10.1016/S0140-6736(99) 04847-3.

10. Heininger U. An internet-based survey on parental attitudes towards immunization. Vac. 2006;24(3739):6351-6355. Epub 2006 Jun 5. doi: 10.1016/j. vaccine.2006.05.029.

11. Angadi MM, Jose AP, Udgiri R, Masali KA, Sorganvi V. A study of knowledge, attitude and practices on immunization of children in urban slums of Bijapur city, Karnataka, India. J Clinic Diag Res: JCDR. 2013;7(12):2803. doi: 10.7860/JCDR/ 2013/ 6565.3763 .

12. Agarwal S, Bhanot A, Goindi G. Understanding and addressing childhood immunization coverage in urban slums. Indian Pediatr. 2005;42(7):653-663.

13. Rao BT, Thakur JS. Vulnerability assessment in slums of union territory, Chandigarh. Ind J Comm Med. 2007;32(3):189-191. doi: 10.4103/0970-0218.36824.

14. National population policy 2000, Ministry of Health and Family Welfare, New Delhi Govt of India 2000.

15. Kapoor R, Vyas S. Awareness and knowledge of mothers of under five children regarding immunization in Ahmedabad. Healthline. 2010;1(1):12-15.

16. Sharma R, Desai VK, Kavishvar A. Assessment of immunization status in the slums of surat by 15 clusters multi indicators cluster survey technique. Indian $\mathrm{J}$ Community Med. 2009;34(2):152-155. doi: 10.4103/ 0970-0218.51222.

17. Mahalingam S, Soori A. Knowledge, Attitude and perceptions of mothers with children under five years of age about vaccination in Mangalore, India. Asian J Med Sci. 2014;5(4):52-57. doi: https://doi.org/ 10.3126/ ajms.v5i4.10306

18. Kumar A, Unnikrishnan B, Rekha T, Mithra P, Kumar N, Kulkarni V, et al. Awareness and attitude regarding breastfeeding and immunization practices among primigravida attending a tertiary care hospital in southern India. J Clinic Diag Res. 2015;9(3):LC01. doi: 10.7860/JCDR/2015/11892.5616

19. Singh MC, Badole CM, Singh MP. Immunization coverage and the knowledge and practice of mothers regarding immunization in rural area. Indian J Public Health. 1994;38(3):103-107. 
20. Manjunath U, Pareek RP. Maternal knowledge and perceptions about the routine immunization program--a study in a semiurban area in Rajasthan. Indian J Med Sci. 2003;57(4):158-163.
21. Kesarwani P, Singh N, Keshari SS, Dixit S. Cross sectional study of immunization coverage in urban slum areas of Lucknow region. Int J Comm Med Pub Health. 2017;4(9):3310-3313. doi: http://dx.doi.org/10.18203/ 2394-6040.ijcmph20173835.

\section{How to cite this article?}

Tiwari A., Vishwakarma K. A study of knowledge, attitude and practice of mothers on immunization of children in urban slums. Int J Pediatr Res.2019;6(10): 547-554.doi:10.17511/ijpr.2019.i10.09 